\title{
Erratum to: Coracoclavicular ligament attachment regions of the Chinese population: a quantitative anatomic study
}

Cheng Xue $\cdot$ Li-Jun Song $\cdot$ Ming Zhang •

Tian-Sheng Zheng $\cdot$ Jia-Hu Fang $\cdot$ Xiang Li

Published online: 8 June 2013

(C) Japanese Association of Anatomists 2013

Erratum to: Anat Sci Int

DOI 10.1007/s12565-013-0179-9

In the original publication of the article, the values in the first column of Table 1, "(11) Trapezoid to anterior margin" and "(1) Trapezoid to posterior margin" were incorrectly published.

It should be actually read as " $(\mathrm{H})$ Trapezoid to anterior margin” and “(I) Trapezoid to posterior margin”.

The online version of the original article can be found under doi:10.1007/s12565-013-0179-9.

C. Xue $\cdot$ L.-J. Song $\cdot$ M. Zhang - T.-S. Zheng ·

J.-H. Fang $(\varangle) \cdot$ X. Li $(\square)$

Department of Orthopedics, The First Affiliated Hospital of

Nanjing Medical University, 300 Guangzhou Road,

Nanjing 210029, Jiangsu, People's Republic of China

e-mail: fjh4508@163.com

X. Li

e-mail: lixiang2003@medmail.com.cn 